\title{
THE ECONOMICS OF TEAMS AMONG TECHNICIANS
}

\author{
Revised October 9, 2000
}

British Journal of Industrial Relations, 39(1):1-25.

ROSEMARY BATT

Department of Human Resource Studies

New York State School of Industrial Labour Relations

Cornell University

Ithaca, NY 14853-3901

Tel: (607) 254-4437

Fax: (607) 255-1836

E-mail: rb41@cornell.edu 


\begin{abstract}
This paper examines the economic logic of organising field technicians into self-managed teams, an approach to work organisation that shifts the division of labour from a hierarchical to horizontal one. Economic efficiencies arise through the integration of direct and indirect labour tasks and the alignment of the organisational structure with the occupational logic of communities of practice among technicians. Self-managed teams absorb the monitoring and coordination tasks of supervisors, substantially reducing indirect labour costs but without adversely affecting objective measures of quality and labour productivity. For technicians, team membership means longer work hours, but higher wages through overtime pay.
\end{abstract}




\section{THE ECONOMICS OF TEAMS AMONG TECHNICIANS}

\section{Introduction}

Over the last two decades, research on teams has shown that the use of self-managed or autonomous teams is associated with improvements in work-related attitudes, behaviours, and performance (Beekun, 1989; Bettenhausen, 1991; Cohen and Bailey, 1997; Cordery et al., 1991; Guzzo and Dickson, 1996; Pearce and Ravlin, 1987; Wall et al., 1986). Most prior research, however, has failed to examine the economic efficiencies of teams. Even when researchers have analysed objective performance outcomes, they have failed to consider labour inputs, or costadjusted outcomes. For example, do the benefits of teams outweigh the costs of up-front and ongoing investment in team meetings or training? If team members absorb the tasks previously done by supervisors, do the workers devote less time to direct production?

This lack of attention to economic efficiencies may be due to the fact that most research on teams uses a psychological or behavioural paradigm and focuses on teams as the unit of analysis. By doing so, researchers fail to capture the full range of changes in the division of labour and how the shift to team-based systems affects the economic efficiencies in the production system as a whole. Self-managed teams redefine the division of labour by shifting hierarchical relations to horizontal ones. In theory, they make the whole system more efficient by integrating direct and indirect functions into a coherent whole.

In addition, few studies have examined the economic costs and benefits of teams for workers relative to management (exceptions include Weisman et al., 1993; Appelbaum et al., 2000). While many studies have examined intrinsic outcomes such as the quality of worklife (QWL) or job satisfaction (see, for example, Wall et al. 1986), and a handful have considered stress and peer-group pressure (see, for example, Barker, 1993), few have quantified extrinsic 
outcomes such as wages and work hours. Do workers in teams, for example, receive higher wages or overtime pay? Do they absorb additional tasks by working smarter, faster, or longer?

This paper focuses on the economic costs and benefits of self-managed teams, defined as groups of individuals who are semi-autonomous or largely self-managing, who are interdependent and are perceived by others as a group, and who have significant relations with other groups in a larger system (Hackman, 1987). It contributes to the research on teams in several ways. First, I examine economic efficiencies in the production system as a whole and show how this approach (rather than a team unit of analysis) produces more meaningful results. I compare objective performance outcomes and the allocation of direct and indirect labour in systems that use self-managed teams versus traditionally supervised groups. Second, I analyse the distribution of costs and benefits associated with self-managed teams: I compare the costs and benefits of teams for management to the wage and hour outcomes for workers. Third, I examine self-managed teams among technical workers -- an understudied occupation that is among the fastest growing and one that is especially important for knowledge-based economies. I use qualitative field research to interpret the quantitative results. I conclude by discussing how the approach used in this study can be applied more generally to other contexts.

This paper considers these questions through a study of 230 technicians in a stratified random sample of self-managed and traditionally supervised groups in a large U.S. telecommunications company. The subjects are field technicians who install and maintain network transmission and switching equipment for a regional Bell operating company (RBOC). In traditional hierarchies, the supervisor is responsible for co-ordination and monitoring of geographically dispersed work groups. Under a self-managed team organisation, the supervisor is removed; and technicians as a team take responsibility for their geographic area. 


\section{Alternative Theoretical Frameworks}

Research on Teams and High Performance Systems

The lack of attention to economic analyses of teams is evident in existing reviews of the literature. In a meta-analysis of 131 North American field studies between 1961 and 1991, for example, Macy and Izumi found that the evidence on the economics of change efforts was scarce and unreliable, with only 16 studies (12\%) including any measures of economic cost (1993:

238). More recently, Cohen and Bailey (1997) reviewed fifty-four studies of teams in organisational context published between 1990 and 1996. They found that most studies analysed outcomes along multiple dimensions (e.g., attitudes, behaviours, subjective and/or objective measures of quality or quantity), but only one (Pearson, 1992), considered labour productivity and only one (Weisman et al., 1993), wage outcomes.

The economic pay-off to teams has figured more prominently in the literature on "high involvement" or "high performance" work systems -- systems in which firms invest in skills and training, employee participation in teams, and HR incentives such as employment security and performance-based pay (see Ichniowski et al., 1996; Wood, 1999). Even these studies, however, usually do not include labour-cost adjusted outcomes or analyses of the allocation of direct and indirect labour. Moreover, the few that have examined wage outcomes provide mixed results. For example, Appelbaum et al. (2000) found that workers in some high performance plants enjoyed higher wages, while Osterman (2000) found that workers in high performance plants had no higher wages and were significantly more likely to experience layoffs.

Three perspectives from the high performance literature, however, are relevant to the current study. First, from an economic perspective, we need to understand production efficiencies at a system level. Studies at the team unit of analysis usually explain performance in 
terms of worker motivation and behaviour. From an economic perspective, what matters is the performance of the production system as a whole, including both direct and indirect labour.

Second, the high performance literature shows that the nature of teams varies widely. Teams vary in the extent to which they have substantive versus consultative decision-making responsibilities (Levine and Tyson, 1990); whether they are the fundamental unit of work organisation (that is, on-line teams) or parallel to that work organisation (that is, "offline") (Cotton, 1993; Rubenstein, 2000); and whether they are used to alter the broader organisational structure. For example, while teams in lean production systems are embedded in vertical hierarchies of co-ordination and control (Adler, 1993), those inspired by socio-technical systems (STS) theory involve greater decentralisation and a shift to horizontal relations of collaboration and co-ordination (Berggren, 1992; Appelbaum and Batt, 1994).

Third, the economic value of teams must be understood in specific industry and occupational contexts. While growing evidence suggests that team-based systems produce better performance in general, research also suggests that the potential for and rationale behind performance gains is contingent on industry and technological context (Appelbaum et. al, 2000; Becker and Gerhart, 1996; Whitfield and Poole, 1997; Wood, 1999). For example, in steel mills, the huge capital outlays in advanced technology mean that machine uptime is the critical performance metric; it is particularly the communication of workers across miles of steel mills that leads to better machine utilisation (Appelbaum et al., 2000). In apparel, it is multi-skilling in self-managed teams that leads to improved throughput time and allows firms to compete on the basis of quick response to market demand (Appelbaum et al., 2000; Abernathy et al., 1999). 


\section{The Rationale for Self-managed Teams Among Technicians}

The use of teams among field technicians differs in at least two important ways from their use among blue collar manufacturing workers. First, manufacturing plants typically have used teams to increase the breadth of tasks and individual discretion of low-skilled workers in jobs that were successfully taylorised, or rationalised, under mass production. The jobs of field technicians, however, were never successfully rationalised. Given that technicians already have considerable skill and discretion, the use of self-managed teams is likely to produce only modest changes in the design of technicians' direct labour tasks.

Second, given high levels of "technically-required interdependence" in manufacturing (Cummings, 1978), team-based systems in factory settings improve performance because they allow production workers to solve problems over an entire process, rather than a piece of it. The work of field technicians, by contrast, requires much less interdependence. Technicians, for example, often work autonomously to install or repair equipment on the premises of individual customers. Thus, it is not readily apparent why technicians should perform better if organised into formal teams. In fact, ethnographic research suggests that technicians already create their own informal "communities of practice," regardless of the formal organisational structure in which they are embedded (Orr, 1996). The field technicians in the current study of telecommunications are very similar to the xerox field technicians in Orr's study. He argues that the technicians should be viewed as an occupational community (Van Maanen and Barley, 1984), rather than an organisational one. Despite the fact that their work locations are geographically dispersed, Orr's xerox technicians met regularly over coffee to discuss their work and confer with each other. Informal teams also characterise the organisation of technical work in a variety of lab settings (Barley, 1996). In sum, field technicians already have the skills, 
discretion, and independence to do their job, to learn from each other, and to work co-operatively where necessary. Why should formal self-managed teams make a difference in this context?

Viewed from the perspective of teams as the unit of analysis, the organisation of technical work via self-managed teams might merely formalise what they are already doing. The production system as a whole, however, involves the effective performance of both direct and indirect labour functions. In technical services, there is reason to believe that the economic benefits of self-managed teams lie more in the effective execution of indirect tasks. Indirect tasks in these settings are non-trivial, and include the two dimensions of co-ordination and monitoring. Co-ordination tasks involve the allocation of labour among technicians who work in widely dispersed locations, which I refer to as internal co-ordination, as well as co-ordination across networks of actors -- workers in different departments, suppliers, and customers -- or external co-ordination. The tasks of monitoring are also considerable because checks are not easily built into the technical system as in manufacturing. Monitoring includes the tasks of inspection, documentation, reporting, and responding to customer complaints. It also includes technical assistance to correct problems found or to respond to changes in technology, staffing, customers, or market conditions. Thus, co-ordination and monitoring involve a series of tasks that are time-consuming and important for the effective maintenance of the technical infrastructure. Thus, the use of self-managed teams among technicians appears to formalise their already existing autonomy with regard to direct production tasks, but introduces for the first time the indirect tasks of co-ordination and monitoring that are usually performed by supervisors in hierarchical organisations.

Self-managed teams are likely to improve organisational efficiency because they shift the division of labour from a hierarchical to a horizontal one. Under vertical hierarchies, technicians 
are responsible for direct tasks and managers, indirect tasks of co-ordination and monitoring. This creates an anomaly because technicians work under the logic of occupational or horizontal communities, but are embedded in large-scale organisations where hierarchical control is the organising principle (see, for example, Barley, 1996:429). Economic inefficiencies arise because the principles of work in technicians' occupational communities are at odds with the logic of vertical hierarchies:

"Most technicians work in organizations that routinely attempt to fold technicians into a vertical division of labor via formal job classifications, graded pay scales, and related human resource practices. Yet technicians remain strongly oriented to their community of practice. Moreover, technical work routinely undermines bureaucratic systems of control and stipulated roles because technicians' expertise and knowledge is a critical resource which few outsiders possess. Thus, technicians' work brings the underpinnings of an occupational division of labor directly to the core of well-established organizational divisions of labour" (Whalley and Barley, 1997:49-50).

Under self-managed teams, by contrast, co-ordination is likely to be more efficient for two reasons. First, third-party transactions costs are eliminated. For example, direct communication between technicians and subject matter experts in other departments (external co-ordination) is more efficient than bringing a third party (supervisor) into the loop. Second, technicians have much greater technical expertise than supervisors, whose skills often become obsolete because of on-going technology change. For example, compared to supervisors, technicians are in a better position to allocate tasks because they know the equipment, customers, and field problems, and which technician is best able to service particular customers or machines. Similarly, technicians' direct knowledge of the equipment puts them in a better 
position to respond to customer complaints. These arguments also apply to monitoring and technical assistance because supervisors' skill obsolescence renders them less able to provide technicians with technical assistance. Peer monitoring and assistance is already embedded in the communities of practice described by Orr, Barley, and others. Getting rid of supervisors, therefore, should improve technical efficiency and eliminate unnecessary indirect costs.

Existing research on technicians, therefore, suggests that the use of self-managed teams should create economic efficiencies by aligning the organisational structure with the logic of technicians occupational skills and work practices. Work organised into self-managed teams should not simply formalise what already exists, but rather change the production system by taking indirect support functions in hierarchical organisations and incorporating them into the conduct of daily work in horizontal organisations.

The question of how self-managed teams influence the use of direct labour among technicians is less straightforward, involving competing factors. On the one hand, self-managed teams may have a positive effect on the conduct of direct labour tasks, especially if the organisational structure prevents occupational communities of practice from operating effectively. According to Whalley and Barley, for example, technicians routinely characterise management and hierarchy as undermining their work (1997:44). This might occur if supervisors with less expertise than technicians typically seek to wield their authority or give misguided orders, or if they disrupt direct lines of communication between technicians and other departments. Another example comes from Bailyn et al. (1999), who found that a product development team was running behind schedule in part because higher managers, who were worried about meeting deadlines, kept interrupting the team members when they were working. Eliminating the supervisor also may allow workers to feel a greater sense of freedom to pursue 
their own initiative, thereby increasing motivation and a sense of pride and responsibility at work. Finally, some research suggests that peer monitoring in self-managed teams is a more powerful mechanism of control than hierarchical monitoring, inducing workers to work harder in order to meet self-imposed group norms and rules (Barker, 1993).

On the other hand, to the extent that technicians spend additional time with customers and suppliers, in meetings, or on inspections and reports, they may spend less time on direct labour activity. Unless technicians work longer hours, their direct labour productivity (usually measured in terms of customers served per day) may actually fall. Another line of reasoning, derived from agency theory (Alchien and Demsetz, 1972), is that technicians freed from the monitoring of a supervisor are more likely to shirk, taking more time for coffee breaks or personal time. If hierarchical monitoring is more effective than peer monitoring in extracting greater effort, then direct labour productivity may fall under team-based systems.

In sum, the hypothesised relationship between self-managed teams and indirect labour costs is negative. The relationship between the use of teams and direct labour productivity of technicians, by contrast, is the net result of competing factors. A key empirical question concerns the magnitude of savings associated with self-managed teams.

\section{The Distribution of Costs and Benefits of Teams}

A further issue is the distribution of relative costs and benefits of workplace innovations for firms and workers. As noted above, most studies of workplace innovations estimate performance benefits without analysing outcomes of interest to workers, such as wages, work hours, or job security. Yet, the sustainability of innovations is likely to depend on whether employees realise some share in performance gains. The distribution of costs and benefits will 
depend on contextual factors, such as whether workers and management have negotiated an explicit agreement as in gain-sharing plans, pay-for-skill plans, or pay for additional tasks.

In the absence of such an agreement, as is true in this case and many others, the outcomes for workers are more ambiguous. To the extent that firms seek to reduce labour costs by shifting supervisors' responsibilities to lower paid workers, there may be pressure on workers to do more work in less time. Another alternative is that employees will work longer hours and receive overtime pay (Weisman et al., 1993). If overtime work is voluntary, then workers may view longer hours as an opportunity and a benefit. If it is involuntary, then workers may gain higher wages but at the expense of time devoted to family or personal life. In the context of the current case, overtime was voluntary and most technicians valued it as a means to increase their income. To assess outcomes for workers in this case, I compare the work and overtime hours of technicians in self-managed and traditional work groups, and then estimate associated overtime pay.

\section{Methods}

The research for this study combined observation of workers, interviews at multiple levels of the organisation, individual surveys, and archival data on performance matched to the individual surveys. The observation and field interviews contributed to understanding the tasks and skill requirements of technicians' work, the differences in responsibilities of technicians in selfmanaged versus traditional groups, and occupation-specific performance measures. The choice of a quantitative study in one company helps to control for variation in firm-level variables such as corporate culture, business strategy, and human resource (HR) policies. A union contract also reduced variation in HR practices (e.g., seniority-based job bidding, compensation). For the 
remainder of the paper, I refer to the self-managed teams as teams and traditionally supervised groups as traditional groups.

\section{Organisational Context}

The company in this case is a large regional Bell operating company (RBOC) in the United States that undertook work innovations in anticipation of heightened competition under deregulated local markets. In 1996, the U.S. Congress passed the Telecommunications Act, which opened local markets to competition. In anticipation of deregulation, the company and union in this study negotiated a voluntary self-managed team initiative as a vehicle for improving quality and customer service. The labour-management agreement specified guidelines for which tasks would be absorbed by the teams. The program was voluntary; technicians as a group could vote to become self-managed. They received no additional pay, but according to field interviews, technicians liked the freedom from supervision and the ability to run their own geographic turf; they also liked the fact that they were less likely to be pulled from their own area to work in another area. Management operated under the theory that each team would take responsibility for a given geographic area, and that the team's sense of responsibility and knowledge of customers, in turn, would provide incentives for more preventative maintenance and better service.

Field research for this study showed that the nature of work among telecommunications technicians is very similar to that described in ethnographic research on other types of technicians (see, for example, Orr, 1996; Barley and Orr, 1997). For example, they have highly specialised skills, work independently to install and maintain equipment in dispersed field locations on customer premises, and have daily routines that help create communities of practice, for example, through informal meetings at coffee shops or in the field. 
Under the self-managed system in this case, the field technicians performed a series of indirect labour functions traditionally done by supervisors, including internal and external coordination and monitoring. First, they were responsible for allocating work among themselves and for ensuring timely completion of jobs. Second, they managed a network of external relationships: they interfaced with customers to bring in jobs or handle complaints, contacted suppliers to order supplies, negotiated with other managers over turf responsibilities, worked with engineering and provisioning for new plant and equipment, and interacted with power companies for co-ordination of joint-use poles (poles used by both the telephone and power companies). Third, they assumed monitoring tasks, including on-site quality and safety inspections, reporting, and technical assistance. Safety monitoring and training are an important part of indirect support tasks because of historic regulation and scrutiny of an industry where electric transmission systems pose significant hazards. The self-managed teams incorporated many of these tasks into their day to day work. They also elected a rotating team leader who spent one day per week on paperwork, including filling out reports, responding to customer complaints, and following up on other co-ordination functions as needed.

\section{Data}

The data consist of a stratified random sample of field technicians in a nine-state region in the United States. I created the sample by first including all existing self-managed teams; then, for each such team, I randomly selected a traditional group that worked under the same district (middle) manager. The sampling strategy produced similar numbers of teams and traditional groups by state and by local service market (e.g., urban, suburban, rural; residential and business customers), except that I over-sampled the traditional groups because of small 
numbers. A random subset of employees in each team or group received surveys, and $58 \%$ responded for a total of 466 surveys.

The quantitative analysis of economic outcomes is based on matching respondent surveys with individual performance data from the company's computer-based measurement system, which tracked the number of dispatches per technician and the resolution of those dispatches. The performance data include individual monthly data for a 17-month period in 1993 and 1994. Of the 466 surveys, matching performance data was available for 230 cases because some states were not fully participating in the information system. Also, the original survey included technicians who worked in central offices or engineering where different performance metrics were used. Usable data for the performance model include 102 technicians from 45 teams and 128 technicians from 49 traditional groups. A comparison of the survey responses of employees with and without matched performance data shows that the latter group was different only with respect to service market characteristics (customer geographic location), which are controlled for in the analyses below.

One methodological question concerns the appropriate time period for comparing the survey data (which captures team characteristics) and the performance data. The performance data covers the period of January, 1993 to May, 1994. The survey was administered in February, 1994. My interpretation of the survey is that it captures fairly stable team characteristics. According to survey responses, only 1 team member reported that he had been in his team for less than 1 year. In addition, of the 45 teams, 37 were formed between 1985 and 1992; 7 were formed in early 1993; and 1 at the beginning of 1994 (for this team, only the 1994 performance data was used). In field interviews, workers said that it usually took a couple of months for the team to learn how to absorb the supervisory tasks. Thus, even for the 1993 teams, they would 
have been acting like a team for most of 1993. I created averages of the performance data on a quarterly basis, 6-month basis, and for the entire 17-month period. Where missing data existed, the average is based on the months for which data was available. The results using data for different time periods were not significantly different, so I report the results below using averages for the 17-month period.

\section{Measures}

Three variables capture work organisation and technology. Team membership is a dummy variable ( 1 represents membership in a team, else traditional group). Multi-skilling is an additive index of the number of different types of jobs routinely performed by the technician (such as installation, repair, splicing, etc.). Technology is the technician's estimate of the percentage of equipment he or she works with that is modernised so that the time and complexity for repairing twisted cable is considerably reduced. Other measures of technological modernisation such as the percentage of copper cable that the technician normally works with produced similar results in equations, and are not included here.

I included 5 types of supportive HR practices because prior literature suggests that team outcomes are likely to be contingent on other managerial practices and support (see, for example, Lawler, 1986; Arthur, 1992; Ichniowski et al., 1996). The HR practices identified in the high involvement literature include off-line problem solving or total quality improvement groups, training, supportive managers, opportunities for advancement, and high relative pay. In this study, total quality group is dummy variable, where 1 equals participation in an offline problemsolving group, else 0 . Training is an additive index of the number of days of formal training received in the 2 years prior to the survey. Supportive management is a six-item scale that measures employees' perceptions of their supervisor (coach) regarding feedback, respect for 
employees, fairness, provision of resources and time, and support for quality (Cronbach's alpha $=$ 85). Skill advancement opportunities is one question that asks the technician's perception of opportunities to improve his or her skills (scale 1-5). Annual earnings are captured by earnings brackets, transformed into the natural log form.

Dependent variables include measures of supervisory tasks, the quantity and distribution of work hours, labour productivity, and objective measures of quality. Supervisory tasks include two dimensions of co-ordination (internal and external) and two dimensions of monitoring (conducting inspections and providing technical assistance). Internal co-ordination is a scale based on five questions that ask how much responsibility technicians have for handling group goals, tasks, schedules, breaks, and absences (scale 1-4, Cronhach's alpha $=.74)$. External coordination is a single question that asks technicians how frequently they contact managers, experts, and others outside of their department to get their job done (scale of 1-5). Inspections is a scale based on two questions that ask technicians how much responsibility they have for quality and safety inspections (scale $1-4$, Cronbach's alpha $=.85$ ). Technical assistance is a $1-5$ scale that asks how frequently technicians help one another with short cuts and problem solving.

Measures of work hours and productivity were computed from monthly data in five categories: a) direct productive labour (hours spent doing service installation and repair); b) unproductive labour, which includes both indirect labour (e.g., meetings and training) and paid time off (vacation, sick leave); c) overtime (over 40 hours per week); d) total work hours (the sum of the prior three categories); and e) number of dispatches that each employee completed. Time in meetings, training, and paid time off is defined as unproductive because it does not contribute to direct labour activity. From the hours and dispatch data, I constructed two measures of labour productivity: productive hours per dispatch per month and total hours per 
dispatch per month. Quality indicators at the individual technician level were of two types: a) missed appointments per month (the number of times a technician missed an appointment when given adequate time to meet it), and b) multiple dispatches per month (the number of times that a technician required additional assistance on a job). No customer satisfaction data was available because the company collected it at a higher level of aggregation than the individual work group

Control variables are: a) employment relations climate (two questions on co-operation between labour and management and between co-workers; b) demographic characteristics (age, gender, years of education, and company tenure); and c) service market characteristics (state location; rural, urban, and suburban location; and residential versus business customers).

\section{Results}

To gain an initial assessment of the similarities and differences of technicians in self-managed and traditional groups, I first estimated the means and standard deviations of variables for all employees, for those in teams, and for those in traditional groups (Table 1). The data show that the sample is very homogenous, as expected, given that this workforce is a stable, unionised one in a company that had not undergone major downsizing or restructuring prior to the time of the study. The average age of technicians is 45 , with a standard deviation of 5.47 . Ninety-six percent of the workforce is male and 92 percent is Caucasian. Skill levels are moderately high, with 98 percent of the sample having at least a high school education and 65 percent at least 1 year of post-secondary college or technical training. Average tenure with the company is 22 years, with a standard deviation of 5.2. Eighty-nine percent of the sample are union members (the company operated in states with right to work laws that allow employees to decide whether or not they want to join the union that has been elected to represent all workers in the workplace). This sample is representative of employees in the traditional Bell system more 
generally, where strong internal labour markets and historic employment security created a very stable, highly skilled, and homogenous, Caucasian workforce (for a further discussion of internal labour markets in the Bell system, see Keefe and Batt, 1997).

The average technician worked 204 hours per month, or 47.2 hours per week. Monthly hours include 157 hours of direct labour time, 15 hours of indirect/unproductive time, and 31 hours of overtime. These data are consistent with reports from field interviews, which indicated there was widespread use of overtime. Labour productivity averaged 2.36 hours per customer per employee, also consistent with reports from the field. This total takes into account residential service calls that are usually quite short as well as those to businesses that are much longer. It also includes driving time, which is considerable in this sample (averaging 1.8 hours per day) due to the high percentage of technicians serving residential and rural populations.

[Insert Table 1 here]

The technicians in teams and traditional groups are similar along many dimensions. They are similar in their demographic characteristics, in their total work hours and overtime, in their objective quality and productivity measures, and in most dimensions of human resource and industrial relations practices (use of new technology, participation in offline problem-solving, advancement opportunities, earnings, labour-management relations, and union membership levels).

Teams and traditional groups differ significantly, however, with respect to work tasks, work hours, training, and employment relations. Technicians in teams are significantly more likely to absorb supervisory tasks of internal and external co-ordination and monitoring (inspections and technical assistance). On average they clocked in about 2 hours per month less productive time and about one and one-half hours more indirect/unproductive time. They had 
more overtime hours, although the mean differences are not significant. Teams also reported significantly more multi-skilling, more formal training (which is primarily team related training), less support from management, and better relations with co-workers.

In the multivariate analyses that follow, I control for these differences. That is, I control for other parts of the human resource system -- dimensions of work that are likely to co-vary with the introduction of teams (such as multi-skilling, team related training, and the reduction in support from the supervisor). Thus, my approach produces a conservative estimate of outcomes associated with team-based systems because it captures the differences resulting from the structure of teamwork alone. Also, there are significant differences in the service markets in which teams and traditional groups are located, so that controlling for market characteristics is important as these are likely to have a significant effect on productivity and quality.

The simple means tests suggest that the team structure does influence what technicians do and how they allocate their work time. To probe these results more carefully, I conducted a series of multivariate analyses that control for other potential explanations for differences between technicians in teams and traditional groups. I used ordinary least squares regressions and ordered probit analyses (where appropriate) for the dependent variables of interest. In all regression analyses I used a Huber correction technique (Huber 1967) because individuals were randomly sampled within traditional groups, a violation of OLS assumptions of independence of observations. Where cluster sampling exists, as in this case, the Huber technique assumes that observations are independent across groups, but not within groups. The alternative variance estimator takes into account the correlations within groups, and thereby produces more robust standard errors. Each regression includes the independent and control variables along with an indicator variable for the team or group to which the observation belongs. For two of the 
dependent variables in Table 2 (external co-ordination and technical assistance), I used an ordered probit via a maximum likelihood technique because the dependent variable is measured on a 5-item multinomial scale.

Each of the analyses uses the same set of independent and control variables, but substitutes different dependent variables. Table 2 reports the results using the four supervisory tasks as the dependent variables. This analysis provides quantitative support for the qualitative evidence that the structure of tasks and routines in self-managed teams is significantly different than that found in traditional groups. After controlling for other potential sources of variance, the analysis shows that technicians in teams are significantly more likely than those in traditional groups to assume responsibility for all four types of indirect or supervisory tasks.

[Insert Table 2 here]

The next question concerns whether absorption of supervisory tasks affects team members' work hours, and the results of regression analyses suggest that it does (Table 3). Compared to workers in traditional groups, team members average about 2 fewer productive hours per month. This finding of less time in productive hours (and simultaneously more time in unproductive hours) is consistent with field interviews with technicians in teams who said they hold regular meetings to organise the way they work together, and received more initial and ongoing training than when they worked under traditional supervision. Analysis of the data by month and by quarter (not shown) shows that no particular time period accounts for these differences. Team members also, on average, work 6 more overtime hours per employee per month. These findings, taken in conjunction with those in Table 2, suggest that members of teams absorb supervisory tasks by working fewer productive hours and more overtime hours. 
It is also noteworthy that offline total quality meetings are much more time-consuming than self-managed team meetings. Employees who participate in offline meetings have 3.2 fewer hours of direct time per month. About equal percentages of technicians in traditional groups ( 18 percent) and self-managed teams (21 percent) participated in offline team meetings.

[Insert Table 3 here]

An important follow-up question is whether technicians in teams and traditional groups differ with respect to direct labour productivity and quality (Table 4). In this case, the data reveal no significant differences in direct labour performance based on team membership. Multiskilling and participation in TQM similarly have no relationship to objective performance measures. An analysis of the data by month and by quarter (not shown) shows no significant differences from these findings.

[Insert Table 4 here]

The results thus far indicate that technicians in teams differ significantly from those in traditional groups in their absorption of indirect labour tasks and in their work hours; but they do not differ significantly in terms of objective measures of labour productivity or service quality. The next question is to translate these findings into labour efficiency at the level of the production unit in order to compare the relative efficiency of the team-based versus traditional work system. If technicians in teams absorb the work of supervisors, which system --- a horizontal or hierarchical division of labour -- is more efficient? One way to assess this question is to compare the time it takes team members as a group to do the work of the supervisor they replace. The previous analysis shows that, compared to technicians in traditional groups, those in teams work 2 hours per month less in direct labour and 6.0 hours more in overtime -- a difference of 8 hours per member per month. As a first approximation, I will 
assume that this time represents the time to complete the added tasks of co-ordination and monitoring, an assumption that is consistent with qualitative evidence from field interviews. In field interviews, team members said that they typically met each morning to assign tasks and coordinate activities. In addition, one team member served as the lead member, and this position rotated on a monthly or bimonthly basis. The lead person worked in direct customer service 4 days a week and would take about 1 day per week to handle quality and safety reports and other paperwork previously handled by the supervisor. The lead would handle most customer complaints and some of the interface with other departments over turf responsibilities, or coordination in pre-survey work or construction projects. In addition, each team member also assumed some tasks of external co-ordination.

To compare the work time of technicians in teams to that of traditional supervisors, I estimated the savings associated with the typical self-managed team. Both the median and mean size of teams is eight members. According to the data, each team member spent roughly 8 hours per month on co-ordination and monitoring, or 64 hours per month per team ( 8 hours $/$ member*8 members per team) to absorb supervisory tasks. A typical full-time supervisor works 174 hours per month (40 hours/week*4.3 weeks/month). However, supervisors also routinely worked overtime, and were paid a straight hourly wage for that time. Supervisors that I surveyed reported working about 40 hours per month in overtime. Data from the corporate Human Resources Department showed that supervisors actually received an average of 26 hours per month in overtime pay. This amount is less than what the supervisors reported for two reasons. First, supervisors' self-reports may be somewhat inflated. Second, the company had a cap on the amount of overtime hours it was willing to pay for supervisors (companies are not legally required to pay supervisors any overtime pay because supervisors are defined as exempt from 
coverage under United States' wage and hour laws). I used the company data because it provides a more accurate estimate of the amount of savings actually incurred by the company. It also provides a more conservative estimate of the real differences in the time it took workers and supervisors to carry out indirect labor tasks. Using this conservative estimate, teams did in 64 hours per month what the average supervisor did in 200 hours per month, a difference of 68 percent.

\section{The Distribution of Costs and Benefits}

Finally, if teams do the work of supervisors in 68 percent less time, then the question is how are the economic benefits of teams distributed? In other words, if team members learn new skills and absorb supervisory tasks, who gains from the economic efficiencies of teams? To translate the hours of work analysis above into labour costs, I used average wage data for technicians and supervisors because real wage data was not available for proprietary reasons. In this case, however, there is little variation in wages except for that associated with overtime hours. This is because the union contract sets one hourly wage grade for field technicians; wage rates vary only by seniority, with employees reaching the highest grade after 5 years of service. Because this study involves employees who average 22 years of service, with a standard deviation of 5 , there is little variation in wages based on seniority. Variation in earnings, therefore, is based almost entirely on variation in work hours. Labour costs for service technicians averaged $\$ 23.80$ per hour in 1995 (loaded estimate including $36 \%$ for benefits). The hourly overtime rate was $\$ 26.25$ (one and a half times the hourly pay of $\$ 17.50$ ). For supervisors, the average total cost of wages and benefits of was $\$ 73,497$ in 1995 (a mid point average salary of $\$ 47,000$ plus $36 \%$ loading for the costs of benefits). The average $\$ 7,000$ in overtime pay brings the average total costs per supervisor to $\$ 80,497$ annually. 
Table 5 presents the estimates of labour cost savings associated with teams in this case. The costs of additional work hours among team members is estimated at 2 hours of straight time (lost direct labour @ \$17.50 per hour) plus 6 hours of overtime per member per month. Assuming that the average size of teams is 8 , additional costs for teams for the employer included 16 hours of straight time per month and 48 hours of over time. The first set of calculations in Table 5 shows that the employer saved $\$ 60,780$ in indirect labour costs per team per year. The second set of calculations shows that the employer shared the savings with team members -- the employer kept $75.5 \%$ of the indirect cost savings while employees received the remaining $24.5 \%$ through longer work hours and overtime pay. This overtime pay represents an annual wage premium for team members of 4.12 percent over the average base plus overtime pay of $\$ 45,850$ received by a typical technician under traditional supervision.

[Insert Table 5 here]

At the organisational level, total indirect cost savings associated with the team system would depend on the percentage of technicians that shifts to self-management. In this case, the team system covered only $5 \%$ of the technician workforce, but $32 \%$ of the survey respondents in traditional groups said they would volunteer for the program if given the opportunity. There were over 3,000 first-line supervisors in network operations at the time of the study. If one-third of the workforce shifted to teams, then reductions of roughly one-third of the supervisory workforce would be possible. In this case, eliminating 1,000 supervisors would result in savings of roughly $\$ 60$ million in annual indirect labour costs.

A potential confound to this study is selection bias because participation in teams was voluntary. Technicians as a group would vote to become a self-managed team. It is plausible that those who volunteered were already assuming responsibilities of co-ordination and 
monitoring -- in other words, it was the individual characteristics of the volunteers, rather than the work design per se that made a difference. One way to consider this issue is to analyse the characteristics of current volunteers for the teams. That is, while there was no opportunity for pre-post test data in this study, I included a survey question asking whether technicians currently under traditional supervision would volunteer for teams if given the opportunity. Using this variable, I redid the analyses in Tables 2, 3, and 4 above, substituting team volunteer for team member. Volunteering had no significant relationship to the variables in question. Similarly, I compared early and later forming teams on the hunch that the early volunteers had more enthusiasm or initiative; I again found no significant differences along the dimensions of interest. Also, in surveys conducted of supervisors and managers, I asked whether technicians' performance was a criteria in the approval of self-managed teams, and the overwhelming response was negative.

In summary, the empirical evidence in this case shows that the primary benefits of selfmanaged teams among field technicians are in labour efficiencies associated with the integration of direct and indirect labour tasks and the elimination of supervisors. Team members did the work of co-ordination and monitoring in 68 percent less time than did traditional supervisors, and did so without adversely affecting other performance measures.

This quantitative evidence also supports the findings from field research with respect to the main effects of the team initiative. In field interviews, I asked technicians in teams how formal teams affected the way they worked. The typical response was to focus on the additional tasks they had to do -- not on the content of the technical work itself, which remained largely unchanged. For example, 
"What's the difference between before and after the self-managed team?....not a whole lot. Now, the deadlines fall on us rather than on someone else. We work and live around here so the customers are our friends. Now, if we do something right, we get the credit -- like the job on highway 531. But we have to deal with customer complaints too... And we have a lot more paper work to do.... We also order all our supplies. If we need cable, we see to it that it's here" (Interview 46, 3/29/93).

These findings raise the question of whether the additional hours of overtime in the teams represents time actually worked, or whether team members were padding their work hours to get more overtime pay. This study cannot resolve that question since it is not possible to assess whether the additional 64 hours per team per month was a reasonable amount of time to accomplish indirect labour tasks. The relevant comparison, however, is with the supervisors' work time; and it is equally plausible that supervisors took advantage of their position to pad their own overtime hours. The analysis shows that the teams were at least two-thirds more efficient than the supervisors.

A final question is whether the supervisory structure provides other benefits to the organisation that teams cannot provide. In this case, there was no information in field interviews to support this idea. Supervisors who became coaches of teams increased their span of control (overseeing teams plus traditional groups), and spent more time on coaching or training. Some managers in field interviews, however, complained about one downside of teams that was unrelated to the presence or absence of the supervisor per se. The issue was less labour flexibility. Because teams were assigned to manage their own territory of a given region, managers responsible for the whole geographic region were not allowed to re-allocate team 
members from one territory to another, except in cases of extreme emergencies. I do not have the quantitative data to assess whether this issue was a widespread concern or not.

\section{Conclusions}

This paper contributes to the literature on teams by examining the economic pay-off to teams in an occupation that is economically important but that has received little attention. The business case for teams of technicians appears to rest heavily on the system-level efficiencies gained through the alignment of the organisational structure with the informal work characteristics of the occupational community. The case demonstrates the value of research that examines the nature of teams and what they actually do in the context of specific occupations and industries. In this case, organisational efficiencies accrued from the specific use of self-managed teams, but not offline problem solving teams. Self-managed teams provide a mechanism for changing the vertical division of labour into a more horizontal one. Other types of team-based systems, such as such as offline or total quality problem-solving groups, tend to leave the supervisory structure in tact, and thus are unlikely to lead to savings in indirect labour costs. Some studies, for example, have shown that the role of supervisors actually increases under new forms of teambased organisation, as in Lowe's (1993) study of Japanese-style lean production where teambased work organisation exists, but in a highly supervised environment. Also, Hoffer-Gittell's (1996) study of the airline industry found that the co-ordinating role of supervisors increased with the use of cross-functional teams. Thus, while many advocates of teams assert that they facilitate the streamlining of bureaucratic organisations, this is likely to be true only in the case of teams that include significant levels of self-management or autonomy.

The finding that technicians absorbed co-ordination and monitoring tasks without affecting objective performance is somewhat surprising from different theoretical points of view. 
On the one hand, for those who believe that teams have powerful motivational affects, or that peer-group monitoring is more powerful than hierarchical monitoring, it is surprising there are no positive findings related to performance. In field interviews, for example, technicians in teams reported that they were more motivated to do preventative maintenance because they knew they would be the ones responsible for going returning to the site if problems were not corrected. If these changes in behaviour were extensive, they did not show up in the performance data.

On the other hand, for those who worry about agency problems and workers shirking in the absence of supervisory monitoring, it is surprising that productivity did not fall. However, the literature on technicians provides a reasonable explanation -- that technicians' occupational identity is already their major source of work motivation. As Orr notes, "They [technicians] are focused on the work, not on the organisation, and the only valued status is that of full member of the community, that is, being considered a competent technician" (Orr 1996:76). In sum, the business case for teams among technicians rests more on system-level efficiencies than on good service, which technicians' own sense of pride at work inspires.

Also, it is noteworthy that workers did share in at least a portion of the productivity gains associated with team efficiencies. Overtime was not mandatory because the self-managed team program was voluntary; and the teams had the option of returning to traditional supervision at any time, but only 7 teams of nearly 200 in the entire company did so. Alternatively, it could be that overtime pay was the payoff to technicians for assuming new tasks. Overtime pay was highly valued because it was the only opportunity for workers to earn higher wages; and equal opportunity for overtime pay was a perennial labour-management issue in this case, as in many others. Technicians in teams gained a modest pay premium as a share in the gains of a productivity-enhancing work innovation. The pay may also be viewed as a premium for learning 
new skills. In the labour economics literature, for example, empirical research finds growing wage variation within occupational traditional groups, and associates that growth with skillbiased technological change, broadly conceived. In this case, one could argue that the technology is the social technology of reorganising work, which changes the skill requirements of some jobs within an occupation and creates opportunities for greater wage variation within an otherwise homogenous group.

The concepts and methodology from this study also are generalizable beyond technical workers. First, savings in indirect labour costs associated with self-managed are likely to exist for production workers in manufacturing and other settings; the empirical question is to estimate the magnitude of those savings. Second, the study demonstrates the value of a system-level approach. If teams in this case are evaluated only in terms of members' labour productivity and quality, then the experiment might be considered a failure; measured at the system level, however, the company accrued significant efficiencies.

Third, this study suggests an approach to team research that incorporates an analysis of the economics of labour, a dimension of teams that has received little attention. While this study has focused on the incorporation of indirect tasks into the work of technicians, it appears that production-level workers are increasingly asked to co-ordinate and negotiate with suppliers and/or customers along the supply chain. Researchers have not examined how the incorporation of these tasks affects labour costs, hours of work, or the distribution of costs and benefits for firms and workers. This study provides a model for analysing direct and indirect labour as important components in the production system as a whole. Because data on work hours and labour costs must be kept for legal and accounting purposes, these data are reliable and accessible from management information systems. Researchers interested in organisational 
change would find it relatively simple to incorporate hours of work and labour cost analyses into their performance models. This type of analysis provides a needed input for interpreting occupation-specific outcome measures that are increasingly used in empirical research on teams.

Finally, hours of work and wage data also provide the opportunity to examine how work innovations affect the workloads and wages of employees, extrinsic outcomes that have received little attention. In the literature on participation and industrial performance, few empirical studies examine wage outcomes for employees. In general, then, the literature on teams would benefit from comparative studies that analyse the hours of work, labour costs, and wages associated with teams across a range of skill levels, occupational groups, and industrial settings. 


\section{REFERENCES}

Abernathy, F. H., Dunlop, J.T, Hammond, J.H., and Weil, D. (1999). A stitch in time: Lean retailing and the transformation of manufacturing. New York and Oxford: Oxford University Press.

Adler, P. (1993). "The 'Learning bureaucracy': New United Motor Manufacturing, Inc." In Barry Shaw and Larry Cummings, eds., Research in Organisational Behaviour 15:111-194.

Alchian, A. and Demsetz, H. (1972). "Production, information costs, and economic organization." American Economic Review 62:777-95.

Appelbaum, E., Bailey, T., Berg, P., and Kalleberg, A. (2000). Mamufacturing Advantage. Ithaca: Cornell University Press.

Appelbaum, E., and Batt, R. (1994). The New American Workplace: Transforming Work Systems in the United States. Ithaca, NY: Cornell ILR Press.

Barker, J.R. (1993). "Tightening the iron cage: Concertive control in self-managing teams." Administrative Science Quarterly, 38, 408-437.

Barley, S. (1996). "Technicians in the workplace: Ethnographic evidence for bringing work into organisation studies." Administrative Science Quarterly, 41:404-441.

Barley, S., and Orr, J. (1997). Between Craft and Science: Technical Work in U.S. Settings. Ithaca: Cornell University ILR Press.

Bailyn, L., Rapoport, R., Kolb, D., and Fletcher, J. K. (1999). "Re-linking work and family: A catalyst for organizational change." In M. P. Cunha and C. A. Marques (Eds.), Reading in organization science: Organizational change in a changing context . Portugal: Instituto Superior de Psycologia Aplicada.

Beekun, R. I. (1989). "Assessing the effectiveness of sociotechnical interventions: Antidote or fad?" Human Relations, 47: 877-897.

Becker, B. and Gerhart, B. (1996). "Special research forum: Human resource management and organisational performance." Academy of Management Journal, 39(4)(August).

Berggren, C. (1992). Alternatives to Lean Production: Work Organization in the Swedish Auto Industry. Ithaca, NY: Cornell University ILR Press.

Bettenhausen, K. L. (1991). "Five years of group research: What we have learned and what needs to be addressed." Journal of Management, 17(2): 345-381.

Cohen, S., and Bailey, D. (1997). "Trends in team effectiveness research: From the shop floor to the executive suite." Journal of Management, 23(3):239-290. 
Cordery, J. L., W. S. Mueller, and L.M. Smith. 1991. "Attitudinal and Behavioral Effects of Autonomous Group Working: A Longitudinal Field Study." Academy of Management Journal 34(2): 464-76.

Cotton, J. L. (1993). Employee Involvement: Methods for improving performance and work attitudes. Newbury Park: Sage Publications.

Cummings, T. G. (1978). "Self-regulating work traditional groups: A socio-technical synthesis." Academy of Management Review, (July): 625-634.

Guzzo, R. A., and Dickson, M. W. (1996). "Teams in organisations: Recent research on performance and effectiveness." Anmual Review of Psychology, 47: 307-338.

Hackman, J. R. (1987). "The Design of Work Teams." In Lorsch, J. W. (ed.), Handbook of organisational behaviour: 315-342. Englewood Cliffs, NJ: Prentice-Hall.

Hoffer-Gittell, J. (1996). Co-ordination, control, and performance of interdependent work processes. Working Paper, Harvard Business School, October.

Huber, P. J. (1967). "The behaviour of maximum likelihood estimates under non-standard conditions." Proceedings of the Fifth Berkeley Symposium on Mathematical Statistics and Probability, 1: 221-233.

Ichniowski, C., Shaw, K., and Prennushi, G. (1997). "The effects of human resource management practices on productivity: A study of steel finishing lines." American Economic Review. 87(3): 291-313.

Ichniowski, C., Kochan, T., Levine, D., Olson, C., and Strauss, G. (1996). "What works at work: Overview and assessment." Industrial Relations, 35(3): 299-334.

Keefe, J., and Batt, R. 1997. "Restructuring Telecommunications Services in the United States." In Harry Katz, ed., Telecommunications: Restructuring of Work and Employment Relations Worldwide. Ithaca: Cornell University ILR Press.

Lowe, J. 1993. "Manufacturing reform and the changing role of the production supervisor: The case of the automobile industry." Journal of Management Studies, 30(5) (September): 23222380 .

MacDuffie, J. P. (1995). “Human resource bundles and manufacturing performance: Organisational logic and flexible production systems in the world auto industry." Industrial and Labour Relations Review, 48(2)(January): 197-221.

Macy, B. A., and Izumi, H. (1993). "Organisational change, design, and work innovation: A meta-analysis of 131 North American field studies--1961-1991." Research in Organisational Change and Development, 7: 235-313. 
Orr, J. (1996). Talking About Machines: An Ethnography of a Modern Job. Ithaca: Cornell University ILR Press.

Osterman, P. (2000). "Work Organization in an Era of Restructuring: Trends in Diffusion and Impacts on Employee Welfare." Industrial and Labor Relations Review, 53(2):179-96.

Pearce, J. A. and E. C. Ravlin. 1987. "The Design and Activation of Self-Regulating Work Traditional groups." Human Relations 40(11): 751-781.

Pearson, C. A. L. (1992). "Autonomous worktraditional groups: An evaluation at an industrial site." Human Relations, 45(9): 905-936.

Rubenstein, Saul. (2000). "The Impact of Co-management on Quality Performance: The Case of the Saturn Corporation." Industrial and Labour Relations Review, 53(2):197-218.

Van Maanan, J., and Barley, S. (1984). "Occupational communities: Culture and control in organisations." In B. Staw and L. Cummings, (eds.), Research in Organisational Behaviour, Greenwich, CT: JAI Press, 6: 287-365.

Wall, T., Kemp, N., Jackson, P., Clegg, P. (1986). "Outcomes of autonomous work traditional groups: A long-term field experiment." Academy of Management Journal, 2: 280-304.

Weisman, C. S., Gordon, D. L., and Cassard, S. D. (1993). "The effects of unit selfmanagement on hospital nurses' work process, work satisfaction, and retention." Medical Care, 31(5): 381-393.

Whalley, P., and Barley, S. (1997). "Technical work in the division of labour: Stalking the wily anomaly." In Barley, S. and Orr, J., Between Craft and Science: Technical Work in U.S. Settings. Ithaca: Cornell University ILR Press, pp. 23-52.

Whitfield, K., and Poole, M. (1997). Special issue on high performance work organisation. Organization Studies. 18(5):745-874.

Wood, S. (1999). "Human resource management and performance." International Journal of Management Reviews, 1(4):367-413. 
TABLE 1

Means of Variables:

All Technicians, Self-managed Teams, and Traditional Groups

Variable

Dependent Variables

Supervisory Tasks

Quality and safety inspections

Technical assistance

Internal co-ordination

External co-ordination

Objective Performance

Productive hours/mo.

Unproductive hours/mo.

Overtime hours/mo.

Total hours/mo.

Productive hrs/dispatch/mo.

Total hrs/dispatch/mo.

Missed appointments/mo.

Multiple dispatches/mo.

Work Design and Technology

SMT member

Multi-skilling

Technology (\% new plant)

\section{Human Resource Practices}

Total quality group

Formal training

Supportive management

Skill advancement opportunities

Annual earnings

\section{Employment Relations}

Positive work group relations

Positive labour-mgmnt. relations

Union membership

$\begin{array}{rrrr}\begin{array}{r}\text { All } \\ \text { Mean }\end{array} & \text { Std. Dev. } & \begin{array}{c}\text { Teams } \\ \text { Mean }\end{array} & \begin{array}{r}\text { Groups } \\ \text { Mean }\end{array} \\ 2.16 & 0.60 & 2.40 * * * & 1.97 \\ 3.21 & 1.27 & 3.76 * * * & 2.76 \\ 2.29 & 0.74 & 2.70 * * * & 1.97 \\ 2.48 & 1.17 & 2.94 * * * & 2.12\end{array}$

$\begin{array}{rrrr}157.34 & 5.29 & 156.15 * * * & 158.28 \\ 15.44 & 5.23 & 16.18 * * & 14.85 \\ 31.02 & 18.77 & 32.25 & 30.04 \\ 203.80 & 19.36 & 204.58 & 203.17 \\ 2.36 & 0.74 & 2.35 & 2.37 \\ 3.05 & 0.95 & 3.07 & 3.03 \\ 1.32 & 1.13 & 1.29 & 1.34 \\ 7.64 & 3.53 & 7.70 & 7.59\end{array}$

$0.44 \quad 0.50$

$6.42 \quad 2.31$

$6.76 *$

6.15

80.08

16.15

78.47

81.41

$\begin{array}{rrrr}0.20 & 0.40 & 0.22 & 0.18 \\ 5.90 & 8.62 & 7.03 * & 4.99 \\ 3.26 & 0.95 & 3.12 * & 3.37 \\ 2.54 & 1.19 & 2.58 & 2.51 \\ 46,586 & 8,603 & 46,683 & 46,507\end{array}$

$\begin{array}{llll}4.26 & 0.78 & 4.46 * * * & 4.10 \\ 3.19 & 1.02 & 3.25 & 3.14 \\ 0.89 & 0.31 & 0.91 & 0.88\end{array}$

* Teams and traditional groups are significantly different at: $* * *=p<.01 ; * *=.05 ; *=\mathrm{p}<.10$ based on Analysis of Variance (ANOVA). 
TABLE 1 (continued)

Means of Variables:

All Technicians, Self-managed Teams, and Traditional groups

Variable

\section{Demographic Characteristics}

Age (years)

Gender ( $\%$ female)

Race (\% Caucasian)

Company tenure (years)

Education (years)

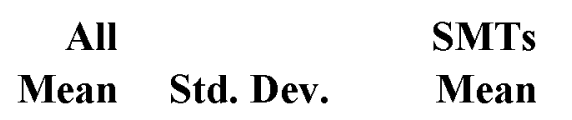

44.86

0.04

0.92

22.00

12.91
5.47

0.20

0.28

5.20

1.13
44.96

0.02

0.92

22.22

12.79
TWGs

Mean

44.79

0.06

0.910

21.82

13.00

\section{Service Market Characteristics}

\section{State Location}

State 1

0.04

0.20

0.03

0.05

State2

0.05

0.21

0.05

0.05

0.30

0.46

0.27

0.31

State 4

0.04

0.19

$0.01 * *$

0.06

0.14

0.35

$0.19 *$

0.10

State6

0.17

0.38

$0.26 * * *$

0.09

State7

0.14

0.35

0.13

0.16

State8

0.12

0.33

$0.06^{* * *}$

0.17

\section{Geographic Location}

Rural

$\begin{array}{llll}0.43 & 0.50 & 0.52 * * * & 0.35 \\ 0.26 & 0.44 & 0.25 & 0.27 \\ 0.23 & 0.42 & 0.94 * * & 0.82\end{array}$

Urban

Suburban

\section{Customer Base}

Residential

Small business

Large business

$\begin{array}{llll}0.87 & 0.33 & 0.94 * * * & 0.82 \\ 0.06 & 0.24 & 0.08 & 0.05 \\ 0.02 & 0.15 & 0.08 & 0.08\end{array}$

* Teams and traditional groups are significantly different at: $* * *=p<.01 ; * *=.05 ; *=p<.10$, based on ANOVA. 
TABLE 2

Teams and the Execution of Supervisory Tasks

$\begin{array}{cccc}\text { Internal } & \text { External } & \text { Inspections } & \text { Technical } \\ \text { Co-ordination } & \text { Co-ordination } & & \text { Assistance }\end{array}$

$\begin{array}{lcccr}\text { Work Design and Technology } & & & \\ \text { Self-managed team } & 0.64 * * * & 0.86 * * * & 0.41 * * * & 0.84 * * * \\ \text { membership } & (0.12) & (0.22) & (0.12) & (0.19) \\ \text { Multi-skilling } & 0.00 & 0.07 * & 0.02 & 0.07 \\ & (0.02) & (0.04) & (0.02) & (0.05) \\ \text { Technology } & 0.00 & 0.00 & 0.00 & -0.01 \\ & (0.00) & (0.01) & (0.00) & (0.00)\end{array}$

Human Resource Practices

Off-line problem-solving

$-0.02$

0.22

$-0.10$

0.16

$(0.15)$

$(0.25)$

$(0.12)$

$(0.24)$

Training

0.00

0.00

$0.04 * * *$

Supportive management

$(0.01)$

$(0.01)$

0.00

$(0.01)$

0.04

0.19

$(0.00)$

0.12

$(0.05)$

$(0.11)$

0.08

$(0.11)$

Skill advancement

0.06

$0.23 * *$

(0.05)

0.00

$0.19 * *$

opportunities

$(0.05)$

(0.09)

(0.04)

(0.09)

Log annual earnings

$-0.18$

0.24

$-0.45$

0.74

(0.32)

(0.54)

(0.36)

(0.67)

Sample size

184

185

184

182

Adj. R-squared

0.46

0.14

0.30

0.18

Standard errors in parenthesis.

Significant differences: $* * *=p<.01 ; * *=p<.05 ; *=p<.10$, based on ANOVA.

Controls for employment relations, demographic characteristics, and location not shown. 
TABLE 3

Determinants of Work Hours and Overtime

Productive

Hours/Mo.

Work Design and Technology

SMT membership

Multi-skilling

Technology

\section{Human Resource Practices}

Off-line problem-solving

Training

Supportive management

Skill advancement opportunities

Log annual earnings

Sample size

Adjusted $\mathrm{R}^{2}$
$-1.97 * *$

$(0.84)$

0.29

$(0.23)$

0.01

$(0.02)$

$-3.17 * * *$

$(1.13)$

0.02

$(0.05)$

0.46

$(0.53)$

$-0.25$

$(0.40)$

0.19

(2.43)

185

0.23
Overtime

Hours/Mo.

Standard errors in parenthesis.

Significant differences: $* * *=p<.01 ; * *=p<.05 ; *=p<.10$.

Controls for employment relations, demographic characteristics, and location not shown. 
TABLE 4

Determinants of Labour Productivity and Service Quality

Work Design and Technology

SMT membership

Productive/ Total Hrs./

Hrs./Dispatch Dispatch

Missed

Appts.

Multiple

Multi-skilling

$-0.07$

$(0.13)$

0.03

0.07

0.53

$-0.00$

$(0.19)$

$(0.14)$

$(0.57)$

$(0.02)$

0.01

$-0.01$

0.03

Technology

$-0.00$

$(0.03)$

$(0.04)$

$(0.15)$

$(0.00)$

$-0.00$

$-0.01$

Human Resource Practices

Off-line problem-solving

$$
0.04
$$

$(0.14)$

$-0.01 *$

(0.02)

Training

$-0.00$

$(0.01)$

Supportive management

0.01

$(0.11)$

Skill advancement opportunities

$-0.06$

Log annual earnings

$(0.00)$

$$
0.11
$$

$(0.19)$

$-0.00$

$(0.01)$

0.04

$(0.15)$

$-0.11$

$(0.09)$

$-0.25$

$(0.62)$

$(0.00)$

$-0.14$

$(0.15)$

$-0.01 * *$

$(0.01)$

$-0.03$

$(0.07)$

0.05

$(0.05)$

0.67

$(0.50)$

185

0.23

185

0.58

185
0.26

Adjusted $\mathrm{R}^{2}$

185

0.32

Standard errors in parenthesis.

Significant differences: $* * *=p<.01 ; * *=p<.05 ; *=p<.10$

Controls for employment relations, demographic characteristics and location not shown. 
TABLE 5

Estimated Labour Cost Savings Associated With Self-managed Teams

\begin{tabular}{|c|c|c|}
\hline Cost Category & \multicolumn{2}{|c|}{ Costs and Benefits } \\
\hline \multicolumn{3}{|l|}{ COMPANY SAVINGS: } \\
\hline \multicolumn{3}{|l|}{ Annual costs of traditional supervisor } \\
\hline Annual salary & 73,470 & \\
\hline Annual overtime* & 7,000 & \\
\hline Subtotal & 80,470 & 80,470 \\
\hline \multicolumn{3}{|l|}{ Annual costs of self-managed teams: } \\
\hline $\begin{array}{l}\text { Meeting and training time: } \\
16 \mathrm{hrs} / \mathrm{mo} @ \$ 23.80 / \mathrm{hr}^{*} 12 \mathrm{mos} \text {. }\end{array}$ & 4,570 & \\
\hline $\begin{array}{l}\text { Overtime: } \\
48 \mathrm{hrs} / \mathrm{mo} @ \$ 26.25 / \mathrm{hr} * 12 \mathrm{mos} \text {. }\end{array}$ & 15,120 & \\
\hline Subtotal & 19,690 & $-19,690$ \\
\hline Company Savings per team & & 60,780 \\
\hline \multicolumn{3}{|l|}{ TEAM SHARE IN SAVINGS } \\
\hline Team: annual overtime pay & 15,120 & \\
\hline Company: savings per team & 60,780 & \\
\hline Team pay as \% of company savings & & 24.9 \\
\hline \multicolumn{3}{|l|}{ INDIVIDUAL MEMBER SHARE } \\
\hline Base pay: $\$ 17.50 / \mathrm{hr} * 2080 \mathrm{hrs} / \mathrm{yr}$ & 36,400 & \\
\hline $\begin{array}{l}\text { Regular overtime } \\
\left(\$ 26.25 / \mathrm{hr} * 30 \mathrm{hrs} / \mathrm{mo}^{*} 12 \mathrm{mos} / \mathrm{yr} .\right)\end{array}$ & 9,450 & \\
\hline Annual pay & 45,850 & \\
\hline $\begin{array}{l}\text { Team-related overtime } \\
(\$ 26.25 / \mathrm{hr} * 6 \mathrm{hrs} / \mathrm{mo} * 12 \mathrm{mos} / \mathrm{yr})\end{array}$ & 1,890 & \\
\hline Individual \% increase in annual pay & & 4.12 \\
\hline
\end{tabular}

